\title{
Sosyal Bilgiler Dersinde Jigsaw, Grup Araştırması ve Okuma-Yazma-Uygulama Yöntemlerinin Demokratik Tutum Üzerindeki Etkileri*
}

\begin{abstract}
Murat Bayram YILAR $^{* *} \quad$ Ufuk ŞİMŞEK ${ }^{* * *}$
Öz

Bu araştırmanın amacı işbirlikli öğrenme (IÖ) modeli kapsamındaki Jigsaw, Grup Araştırması (GA) ve Okuma-Yazma-Uygulama (OYU) yöntemlerinin ortaokul 6. sinıf öğrencilerinin demokratik tutumları üzerindeki etkisini tespit etmektir. Araştırmanın çalışma gurubunu 6. sınıfta öğrenim gören 92 öğrenci oluşturmaktadır. Araştırma, öntest-sontest deneysel desene göre tasarlanmıştır. Araştırma 3 deney grubu ile yürütülmüştür. 6. sınıf sosyal bilgiler ders kitabında yer alan "Demokrasinin Serüveni (DS)" ünitesinin öğretimi söz konusu işbirlikli yöntemlerle 5 hafta süreyle işlenmiştir. Veri toplama aracı olarak Ural (2010) tarafından geliştirilen Demokratik Tutum Ölçeği (DTÖ) kullanılmıştır. Araştırmadan elde edilen veriler ANOVA ve ANCOVA ile analiz edilmiştir. Araştırma sonuçlarına göre demokratik tutum kazandırmada jigsaw yönteminin diğer iki IÖ yöntemine göre daha etkili olduğu tespit edilmiştir.
\end{abstract}

Anahtar Kelimeler: Jigsaw, Grup Araştırması, Okuma-Yazma-Uygulama, Demokratik Tutum.

\section{The Effects of Jigsaw, Group Investigation and Reading- Writing-Presentation methods on the Democratic Attitude at the Social Studies Lesson}

\begin{abstract}
The aim of this study is to determine the effect of the jigsaw, group investigation (GI) and readingwriting-presentation (RWP) methods which are used in cooperative learning (CL) on the democratic attitude of secondary school 6th grade students. The sample of study consisted of 92 6th-class students. The study which used pre-test/post-test experimental design was conducted with three experimental groups. The unit of "Democracy's Adventure (DA)" in the social studies course was taught to the each experimental groups by using the mentioned methods in a 5-weeks period. As the data collection tool, the Democratic Attitude Scale (DAS) developed by the Ural (2010) was used in the research as both pretest and posttest. The data obtained from the study were analyzed
\end{abstract}

\footnotetext{
* Bu makalede kullanılan veriler, “Sosyal bilgiler dersinde işbirlikli öğrenme yöntemlerinin öğrencilerin akademik başarılarına, demokratik tutumlarına ve sosyal becerilerine etkileri" başlıklı doktora tez çalışmasının bir bölümüne aittir.

** Yrd. Doç. Dr., Ondokuz Mayıs Üniversitesi, bayram.yilar@omu.edu.tr

${ }^{* * *}$ Doç. Dr., Atatürk Üniversitesi, ufukersegun@gmail.com
} 
with ANOVA and ANCOVA. The results of the statistical analysis obtained from the study showed that jigsaw method was more effective than other cooperative learning methods in gaining democratic attitudes.

Keywords: Jigsaw, Group Investigation, Reading-Writing-Presentation, Democratic Attitude.

\section{GİRIŞ}

Demokratik vatandaş yetiştirme, ileri toplumlardaki eğitimin temel amaçlarından biridir. Demokratik bir toplum inşa etmede bireylerin demokrasiyle ilgili teorik bilgileri bilmesi çok fazla bir şey ifade etmez. Asıl önemli olan şey, demokrasinin özümsenerek bir yaşam biçimine dönüştürülmesidir (Yılar, 2015). Demokrasi ya da demokratik yaşam alışkanlıkları ancak demokratik bir eğitim sistemi içerisinde, demokratik kuralların uygulamaya geçirilmesiyle öğrenilebilir (Gömleksiz, 1988; Gürşimşek \& Göregenli, 2004). Demokratik bir toplum oluşturma demokratik eğitim ile sağlanabilir (Edwards, 2008). Çünkü demokratik ilke ve kuralların, öğrenme yaşantıları yoluyla toplumun genç bireylerine kazandırılması demokratik eğitimin amacıdır (Akbaşlı, Yanpar-Yelken \& Sünbül, 2010; Hotaman, 2010). Bu yüzden demokratik eğitim, bireylere demokratik değerleri benimseterek demokratik ilkelerin yaşama geçirilme süreci olarak tanımlanabilir (Toper, 2007).

Demokratik eğitim alan bireylerden, demokratik tutum kazanması beklenir. Demokratik tutum bireyin insanlar, nesneler ve çeşitli olaylarla karşı karşıya kaldığı durumlarda onu demokratik ilkeler çerçevesinde davranışlar göstermeye iten öğrenilmiş eğilimler olarak tanımlanabilir (Gömleksiz, 1993). Büyükkaragöz'e (1994) göre demokratik tutum, öncelikle temel kültürleme kurumu olan eğitim sayesinde yaşantıya dönüştürülüp kazandırılabilir. Çünkü demokratik tutum ve değerler kalıtsal değildir; gerekli ortam sağlanırsa herkes tarafından öğrenilebilir (Harber, 2002).
Genel itibariyle demokratik tutum ve davranışlara sahip özgür düşünceli bireyler yetiştirmek eğitim-öğretimin amacı (Davis, 2003; Blair, 2003) olsa da bu konuda en fazla sorumluluk taşıyan derslerden birinin sosyal bilgiler dersi olduğu söylenilebilir. Fakat her şeyden önce demokratik bir okul kültürü ve demokratik bir sınıf ortamı oluşturulması şarttır (Okutan, 2010). Ayrıca demokrasi eğitiminde başarılı olmak için öğretmen rollerinin yeniden gözden geçirilmesi (Sarı \& Sadık, 2011), öğretmenin faydalı olabilecek tüm yöntemleri kullanma bilgi ve becerisine sahip olması gerekmektedir (Yeşil, 2002). Sadece geleneksel öğretim yöntemleriyle demokrasi anlayışını kazandırmak güçtür (Schweisfurth, 2002). Bu açıdan demokratik tutumların kazandırılmasında öğrenci merkezli eğitim tercih edilmelidir. Çünkü çocuğu eğitmenin ve ona demokratik değerler kazandırmanın en etkili yollarından biri aktif öğretim yöntemlerini işe koşmaktır (Büyükkaragöz \& Kesici, 1996).

Aktif öğretimin en önemli uygulamalarından biri de işbirlikli öğrenme (İÖ) modelidir. Çünkü İÖ demokratik tutum kazandırmada büyük bir öneme sahiptir (Gömleksiz, 1993; Schul, 2011; Şimşek, Doymuş, Şimşek \& Özdemir, 2004). Bu yönüyle de sosyal bilgiler dersinin demokratik vatandaş yetiştirme amacına hizmet etmektedir. İÖ modeli, öğrencilere başkalarıyla iyi geçinme ve işbirliği yapma becerisi, sorumluluk bilinci ve demokratik yaşama alışkanlığı kazandırmada kullanılabilecek önemli bir yöntemdir (Cin, 2005; Senemoğlu, 2005). Ayrıca bu yöntem kişinin kendi görüşünü ortaya koyması, toplumun kurallarını benimseyerek bunlara uyması ve toplumsal kişilik kazanmasında etkili olmaktadır (Cin, 2005). 
İÖ'de bireyler birlikte çalışmak zorunda oldukları için birbirine yardım etme davranışını da kazanmaktadirlar (Stamovlasis, Dimos \& Tsaparlis, 2006). Yardımlaşma sürecinde öğrenciler birbirlerinin düşünme biçimlerini keşfettiklerinden bu deneyimler onlara yeni bakış açıları kazandırmaktadır (Webb, 1982).

Tüm bu nedenlerden dolayı İÖ modelinin sınıftaki uygulamaları sayesinde öğrencilerin daha kolay demokratik tutum kazanabileceği söylenebilir (Sönmez, 2001; Yeşil, 2001). Nitekim İÖ’nün demokratik tutum kazandırmada etkili bir model olduğu birçok araştırmada (Bawn, 2007; Demirtaş, 2007; Ebrahim, 2012; Ferguson-Patrick, 2012; Gömleksiz, 1993; Kıncal, 2004; Şimşek ve diğerleri, 2004; Şimşek, Doymuş, Şimşek \& Özdemir, 2006; Şimşek, Doymuş \& Karaçöp, 2009; Yeşil, 2002) ifade edilmiştir. Bununla birlikte bilinmesi gerekir ki aslında İÖ bir şemsiye kavramdır (Smith \& MacGregor, 1992) ve birlikte öğrenme, takımoyun-turnuva, akademik çelişki, jigsaw, grup araştırması, işbirliği-işbirliği, takım-desteklibireyselleştirme, birlikte soralım-birlikte öğrenelim, düşün-eşleş-paylaş, işbirlikli eleştiri gibi birçok farklı yöntem ve tekniği kapsamaktadır. Söz konusu yöntem ve tekniklerin hepsi İÖ'nin temel ilkelerini içermekle beraber grupların yapılandırılması ve dersin işleniş aşamaları farklılık göstermektedir (Yılar, 2015). Alan yazında ise söz konusu bu yöntem ve tekniklerin demokratik tutum üzerindeki etkilerinin birbirleriyle karşılaştırıldığı nicel çalışmaların oldukça sınırlı olduğu görülmektedir. Bu bakımdan araştırmanın alan yazına katkı sağlayacağı düşünülmektedir.

\subsection{Araştırmanın amacı}

$\mathrm{Bu}$ araştırmanın amacı; 6. sınıf sosyal bilgiler ders kitabında yer alan Demokrasinin Serüveni (DS) ünitesinin öğretiminde jigsaw, grup araştırması (GA) ve okuma-yazma-uygulama (OYU) yöntemlerinin öğrencilerin demokratik tutumları üzerindeki etkilerini tespit etmektir. $\mathrm{Bu}$ nedenle öğrencilerin demokratik tutumları üzerinde İÖ yöntemlerinden hangisi ya da hangilerinin daha etkili olduğu araştırılmıştır.

\subsection{Problem Cümlesi}

Sosyal bilgiler dersi DS ünitesinin öğretiminde kullanılan jigsaw, GA ve OYU yöntemlerinin deney gruplarındaki öğrencilerin demokratik tutumları üzerinde etkileri var mıdır?

\subsection{Alt Problemler}

1.Deney gruplarının kendi içinde Demokratik Tutum Ölçeği (DTÖ) öntest-sontest puanları arasında anlamlı düzeyde farklılık var mıdır?

2.Deney grupları arasında DTÖ öntest-sontest puanları arasında anlamlı farklılık var mıdır?

\section{YÖNTEM}

\subsection{Araştırmanın Modeli}

Genel manada deneysel desenlerin esas amac1, değişkenler arasındaki sebep-sonuç ilişkisini test etmektir. (Büyüköztürk, 2011). Bu çalışmada jigsaw, GA ve OYU yöntemlerinin deney gruplarındaki öğrencilerin demokratik tutumlarına etkisini belirlemek amaciyla nicel araştırma yöntemlerinden kontrol grupsuz öntestsontest deneysel desen kullanılmıştır. Kontrol grubu olmayan bu modelde grup ya da gruplara öntest, deneysel işlem başlamadan önce verilerek başarı durumu saptanmaktadır. Deneysel işlem bittikten sonra aynı test aynı gruplara sontest olarak verilir ve deneysel işlemin etkisi bu iki test arasındaki farka göre değerlendirilir. Bu desen sosyal bilimlerde sıkça kullanılmaktadır. Özellikle öntestin kullanılmadığı, kontrol grupsuz sontest desene göre daha uygun, kullanışlı ve etkili bir desendir (Kaptan, 1998; Sönmez \& Alacapınar, 2013). 


\section{2 Çalışma Grubu}

$\mathrm{Bu}$ araştırmanın çalışma grubunu 2012-2013 eğitim-öğretim yılının bahar döneminde, Erzurum'daki bir ortaokulda öğrenim görmekte olan toplam 92 öğrenci oluşturmaktadır (43 erkek, 49 kı). Jigsaw, GA ve OYU yöntemlerinin hangi sınıfta uygulanacağı rastgele (random) yöntemle belirlenmiştir. Fakat sınıflara uygulanacak yöntemler belirlendikten sonra her bir sınıfta işbirlikli gruplar oluşturulurken öğrencilerin 4. ve 5. sınıf ile 6. sınıfın güz dönemine ait sosyal bilgiler dersi başarı notları ve cinsiyetleri dikkate alınarak heterojen gruplar oluşturulmuştur. Deney grubu öğrencilerinin sayı ve cinsiyete göre dağılımları Tablo 1.'de verilmiştir.

Tablo 1. Deney Grubu Öğrencilerinin Sayıları ve Cinsiyete Göre Dağılımları

\begin{tabular}{|c|c|c|c|c|}
\hline \multirow{2}{*}{ Siniflar } & \multirow{2}{*}{ Deney Grupları } & \multicolumn{2}{|c|}{ Cinsiyet } & \multirow{2}{*}{ Toplam } \\
\hline & & $\mathrm{K} 1 \mathrm{z}$ & Erkek & \\
\hline 6/A & OYU Grubu (OYUG) & 19 & 13 & 32 \\
\hline 6/C & Jigsaw Grubu (JG) & 15 & 15 & 30 \\
\hline \multirow[t]{2}{*}{ 6/D } & GA Grubu (GAG) & 15 & 15 & 30 \\
\hline & Toplam & 49 & 43 & 92 \\
\hline
\end{tabular}

\subsection{Veri Toplama Araci}

Araştırmada kullanılan “Demokratik Tutum Ölçeği" (DTÖ) ortaokul öğrencilerinin demokratik tutum düzeylerini incelemek amaciyla Ural (2010) tarafından geliştirilmiştir.

Toplam 34 maddeli ölçek “(1) Hiçbir zaman, (2) Nadiren, (3) Ara sıra, (4) Genellikle, (5) Her zaman" seçenekleri şeklinde 5'li likert tipi maddelerden oluşmaktadır. DTÖ'den alınabilecek en düşük puan 34 en yüksek puan ise 170 'tir. Güvenirlik katsayısı 0.94 olan ölçek (Ural, 2010), deney gruplarına öntest ve sontest olarak uygulanmıştır.

\subsection{Deneysel İşlem}

Sosyal bilgiler dersinin öğretiminde İÖ modelinin jigsaw, GA ve OYU yöntemlerinin demokratik tutum üzerindeki etkililiklerini karşılaştırmak için üç deney grubu oluşturulmuştur. Daha sonra DTÖ, uygulama safhasından önce her bir deney grubuna öntest olarak uygulanmıştır. Sonrasında 5 hafta boyunca haftada 3'er ders saati olmak üzere DS ünitesi söz konusu IOÖ yöntemlerine uygun olarak işlenmiştir. Ders kitabında yer alan ilgili üniteye ait konular ve bunlar için ayrılan saatler Tablo 2.'de verilmiştir.

Tablo 2. Demokrasinin Serüveni Ünitesinde Yer Alan Konular ve Ayrılan Ders Saatleri

\begin{tabular}{|c|c|c|c|}
\hline \multicolumn{4}{|c|}{ Ünite: Demokrasinin Serüveni } \\
\hline Sira & KONULAR & Süre & Uygulama Haftası \\
\hline 1 & Demokrasi Yolunda Az Gittik Uz Gittik & 1 ders saati & \multirow{2}{*}{ 1. Hafta } \\
\hline 2 & Demokratik Toplum Oluşuyor & 2 ders saati & \\
\hline 3 & Başlangıçtan Günümüze Demokrasi Yolculuğumuz & 2 ders saati & \multirow{2}{*}{ 2. Hafta } \\
\hline 4 & Mumu Söndür Kitabı Aç; Kitap Altına da Işık Verir & 1 ders saati & \\
\hline 5 & Temel İnsan Haklarımızı Tanıyalım & 3 ders saati & 3. Hafta \\
\hline 6 & Geçmişten Bugüne Belgelerle İnsan Hakları & 3 ders saati & 4. Hafta \\
\hline 7 & Her Zaman Türk Kadınıyla Birlikteyiz & 2 ders saati & \multirow{2}{*}{ 5. Hafta } \\
\hline 8 & Değerlerimize Sahip Çıkıyoruz & 1 ders saati & \\
\hline
\end{tabular}


Uygulamalar tamamlandiktan hemen sonra ise DTÖ bu kez sontest olarak deney gruplarındaki öğrencilere uygulanmıştır.
Araştırmanın deneysel süreci Tablo 3.'te verilmiştir.

Tablo 3. Deneysel İşlem Süreci

\begin{tabular}{lllll}
\hline Deney Grupları & Deney Öncesi & Deneysel İşlem & & $\begin{array}{l}\text { Deney Sonrası } \\
\text { Son-testler }\end{array}$ \\
\hline JG & Ön-testler & Ünite & Yöntem & DTÖ \\
GAG & DTÖ & DS & Jigsaw & DTÖ \\
OYUG & DTÖ & DS & GA & DTÖ \\
\hline
\end{tabular}

\subsection{Verilerin Analizi}

Araştırmada,

1. Deney gruplarının kendi içinde DTÖ öntestsontest puanları arasında anlamlı düzeyde farklılık olup olmadığını belirlemek için; Bağımlı Gruplar t Testi,

2. Deney gruplarının kendi aralarında DTÖ öntest-sontest puanları arasında anlamlı düzeyde farklılık olup olmadığını belirlemek için; Tanımlayıcı istatistikler, ANOVA, ANCOVA, Bonferroni analizleri yapılmıştır.

\section{BULGULAR VE YORUMLAR}

3.1 Araştırmanın birinci alt problemine ilişkin bulgular ve yorumlar

Birinci alt problemin test edilmesi için her bir grubun DTÖ öntest-sontest puanları kendi içerisinde bağımlı grup t-testiyle analiz edilerek değerlendirilmiş ve elde edilen bulgular Tablo 4a., Tablo 4b. ve Tablo 4c.'de sunulmuştur.

Tablo 4a. JG öğrencilerinin DTÖ öntest-sontest puanlarına ilişkin bağımlı gruplar t testi sonuçları

\begin{tabular}{cllllll}
\hline JG & $\mathrm{N}$ & $\overline{\mathrm{X}}$ & $\mathrm{Ss}$ & $\mathrm{Sd}$ & $\mathrm{T}$ & $\mathrm{p}$ \\
\cline { 2 - 6 } $\begin{array}{c}\text { Öntest } \\
\text { Sontest }\end{array}$ & 29 & 146,68 & 21,799 & 4,048 & $-4,625$ & $\mathbf{0 , 0 0 0}$ \\
\cline { 2 - 6 } & 29 & 165,13 & 4,748 & 0,881 & & \\
\hline
\end{tabular}

Tablo 4a incelendiğinde jigsaw yöntemi ile öğrenim gören öğrencilerin DTÖ öntest puan ortalamaları ile sontest puan ortalamaları arasında anlamlı bir farklılık olduğu görülmekte$\operatorname{dir}[\mathrm{t}=-4,625 ; \mathrm{p}<0.05]$. Bu farklılığa göre $\mathrm{JG}^{\prime}$ deki öğrencilerin uygulama öncesi DTÖ öntest puan ortalamaları 146,68 iken, jigsaw ile yapılan

Tablo 4b. OYUG öğrencilerinin DTÖ öntest-sontest puanlarına ilişkin bağımlı gruplar t testi sonuçları öğretim sonrasında sontest puan ortalamalarının 165,13'e yükseldiği görülmektedir. Bu bulgular, jigsaw yönteminin sosyal bilgiler dersinde öğrencilerin demokratik tutumlarını geliştirmede etkili bir yöntem olduğunu göstermektedir.

\begin{tabular}{|c|c|c|c|c|c|c|}
\hline OYUG & $\mathrm{N}$ & $\bar{X}$ & Ss & $\mathrm{Sd}$ & $T$ & $\mathrm{p}$ \\
\hline Öntest & 30 & 156,73 & 11,122 & 2,030 & \multirow{2}{*}{$-3,608$} & \multirow{2}{*}{0,001} \\
\hline Sontest & 30 & 164,06 & 4,160 & 0,759 & & \\
\hline
\end{tabular}


Tablo 4b incelendiğinde OYU yöntemi ile öğrenim gören öğrencilerin DTÖ öntest puan ortalamaları ile sontest puan ortalamaları arasinda anlamlı bir farklılık olduğu görülmektedir [ $\mathrm{t}=$ 3,608; $\mathrm{p}<0.05]$. Bu farklılığa göre OYUG'daki öğrencilerin uygulama öncesi DTÖ öntest puan ortalamaları 156,73 iken, OYU ile yapılan öğre- tim sonrasinda sontest puan ortalamalarınin 164,06'ya yükseldiği görülmektedir. Bu bulgular, OYU yönteminin sosyal bilgiler dersinde öğrencilerin demokratik tutumlarını geliştirmede etkili bir yöntem olduğunu göstermektedir.

Tablo 4c. GAG öğrencilerinin DTÖ öntest-sontest puanlarına ilişkin bağımlı gruplar t testi sonuçları

\begin{tabular}{cllllll}
\hline GAG & $\mathrm{N}$ & $\overline{\mathrm{X}}$ & $\mathrm{Ss}$ & $\mathrm{Sd}$ & \multicolumn{1}{c}{$\mathrm{T}$} & $\mathrm{p}$ \\
\cline { 2 - 5 } $\begin{array}{c}\text { Öntest } \\
\text { Sontest }\end{array}$ & 29 & 155,41 & 14,753 & 2,739 & $-1,850$ & $\mathbf{0}, \mathbf{0 4 0}$ \\
\cline { 2 - 5 } & 29 & 160,58 & 8,990 & 1,669 & & \\
\hline
\end{tabular}

Tablo 4c incelendiğinde GA yöntemi ile öğrenim gören öğrencilerin DTÖ öntest puan ortalamaları ile sontest puan ortalamaları arasında anlamlı bir farklılık olduğu görülmektedir [ $\mathrm{t}=-$ 1,850; p 0.05]. Bu farklılığa göre GAG'daki öğrencilerin uygulama öncesi DTÖ öntest puan ortalamaları 155,41 iken, GA ile yapılan öğretim sonrasinda sontest puan ortalamalarının 160,58'e yükseldiğ i görülmektedir. Bu bulgular, GA yönteminin sosyal bilgiler dersinde öğren- cilerin demokratik tutumlarını geliştirmede etkili bir yöntem olduğunu göstermektedir.

\subsection{Araştırmanın ikinci alt problemine ilişkin bulgular ve yorumlar}

Araştırmanın ikinci alt problemi için tanımlayıCl istatistikler, ANOVA, ANCOVA ve Bonferroni analizleri yapılmış ve elde edilen bulgular Tablo 5a, Tablo 5b, Tablo 5c, Tablo 5d ve Tablo $5 \mathrm{e}^{\prime} \mathrm{de}$ verilmiştir.

Tablo 5a. DTÖ'nün öntest ve sontestine ait tanımlayıcı istatistikleri

\begin{tabular}{lllcc}
\hline Testler & Gruplar & N & $\overline{\mathrm{X}}$ & SS \\
\hline \multirow{3}{*}{ DTÖ-Öntest } & JG & 29 & 146,69 & 21,800 \\
& GAG & 29 & 155,41 & 14,754 \\
& OYUG & 32 & 156,94 & 10,836 \\
\hline \multirow{3}{*}{ DTÖ-Sontest } & JG & 30 & 165,30 & 4,750 \\
& GAG & 30 & 160,80 & 8,911 \\
& OYUG & 30 & 164,07 & 4,160 \\
\hline
\end{tabular}

Tablo 5a'da grupların demokratik tutum öntest ortalama değerlerine göre OYUG ve GAG'ın ortalamalarının birbirine yakın olduğu, JG'nin ise bu iki gruba göre daha düşük bir ortalamaya sahip olduğu (Xoyug=156,94; $X_{\mathrm{GAG}}=155,41$; $\mathrm{JG}=146,69$ ) görülmektedir. Sontest ortalama değerlerinde ise bütün grupların puan ortalamalarının birbirine yaklaştı $\breve{g}_{1}$ ve öntest puan ortalamalarına göre JG'nin puan ortalamalarındaki artışın diğer gruplara göre daha yüksek olduğu görülmektedir (XoruG=164, 07; $\mathrm{XGAG}_{\mathrm{GA}}$ $\left.=160,80 ; X_{\mathrm{JG}}=165,50\right)$. Demokratik tutum öntest puan ortalamalarındaki farklılıkların istatistiksel olarak anlamlı olup olmadığını belirlemek için ANOVA analizi yapılmış, bulgular Tablo 5b.'de verilmiştir. 
Tablo 5b. DTÖ'nün öntestine ait ANOVA analiz sonuçları

\begin{tabular}{llccccc}
\hline Testler & & Karelerin ortalaması & df & Ortalamaların karesi & F & p \\
\hline \multirow{2}{*}{ Öntest } & Gruplar arası & 1818,006 & 2 & 909,003 & \multirow{2}{*}{3,432} & \multirow{2}{*}{037} \\
\cline { 2 - 5 } & Gruplar içi & 23041,116 & 87 & 264,840 & & \\
\hline
\end{tabular}

Tablo 5b incelendiğinde grupların demokratik tutum öntest puanları arasında (XoYug=156,94; $\mathrm{X}_{\mathrm{GAG}}=155,41 ; \mathrm{X}_{\mathrm{JG}}=146,69$ ve $\mathrm{p}=0,037$ ) anlaml bir farkın olduğu görülmektedir. Grupların demokratik tutum öntest puanları arasında ista- tistiksel olarak belirlenen anlamlı farklılı̆̆ın hangi grubun lehine olduğunu belirlemek için çoklu karşılaştırma testlerinden Bonferroni' ye başvurulmuştur. Analiz sonuçları Tablo 5c.'de verilmiştir.

Tablo 5c. DTÖ öntestinden elde Edilen verilerin Bonferroni analiz sonuçları

\begin{tabular}{|c|c|c|c|c|c|}
\hline Bağımlı değişken & (I) Gruplar & (J) Gruplar & Ortalama farklar (I-J) & Standart hata & $\mathrm{p}$ \\
\hline \multirow{6}{*}{ DTÖ-Öntest } & \multirow{2}{*}{ JG } & OYUG & $-10,248^{*}$ & 4,172 & , 016 \\
\hline & & GAG & $-8,724^{*}$ & 4,274 & ,044 \\
\hline & \multirow{2}{*}{ OYUG } & JG & $10,248^{*}$ & 4,172 & ,016 \\
\hline & & GAG & 1,524 & 4,172 & ,716 \\
\hline & \multirow{2}{*}{ GAG } & JG & $8,724^{*}$ & 4,274 & , 044 \\
\hline & & OYUG & $-1,524$ & 4,172 & ,716 \\
\hline
\end{tabular}

Tablo 5c.'ye bakıldı̆̆ında öntestteki anlamlı farklılığın gruplar arasında GAG ve OYUG'un lehine olduğu görülmektedir (XoYUG=156,94; $X_{\mathrm{GAG}}=155,41 ; \mathrm{X}_{\mathrm{JG}}=146,69 \mathrm{p}=0,016$ ve $\left.\mathrm{p}=0,044\right)$. Bu bulgu demokratik tutum öntest puanlarında JG'nin diğer iki gruba göre daha düşük puan ortalamasına sahip olduğunu dolayısıyla uygulama öncesinde bu grubun demokratik tutum- larının daha düşük düzeyde olduğunu göstermektedir.

DTÖ'nün öntest puan ortalamaları arasında istatistiksel olarak anlamlı farklılıklar olduğu için sontest puan ortalamalarına öntest puan ortalamaları coverate edilerek kovaryans analizi (ANCOVA) ve Bonferroni analizi yapılmış, sonuçlar Tablo 5d ve Tablo 5e'de verilmiştir.

Tablo 5d. DTÖ’n nün Sontestine Ait ANCOVA Analiz Sonuçları

\begin{tabular}{llllll}
\hline Kaynak & Kareler ortalaması & Sd & Ortalamaların karesi & F & $\mathrm{p}$ \\
\hline DTÖ-Öntest & 135,009 & 1 & 135,009 & 3,477 &, 066 \\
Gruplar & 393,524 & 2 & 196,762 & 5,068 &, 008 \\
Hata & 3261,341 & 84 & 38,825 & & \\
Düzeltilmiș toplam & 3725,455 & 87 & & & \\
\hline
\end{tabular}

Tablo 5d incelendiğinde, grupların demokratik tutum sontest puanları arasında anlamlı bir farkın olduğu görülmektedir $(\mathrm{p}=0,008)$. Grupların demokratik tutum sontest puanları ara- sinda istatistiksel olarak belirlenen anlamlı farklılığın hangi grubun lehine olduğunu belirlemek için Bonferroni ile analiz yapılmış ve sonuçlar Tablo 5e.'de verilmiştir. 
Tablo 5e. DTÖ Sontestinden Elde Edilen Verilerin Bonferroni Analiz Sonuçları

\begin{tabular}{llccc}
\hline (I) Gruplar & (J) Gruplar & Ortalama farklar (I-J) & Std. hata & P \\
\hline \multirow{2}{*}{ JG } & OYUG & 1,841 & 1,674 &, 275 \\
& GAG & $5,220^{*}$ & 1,675 &, 003 \\
\hline \multirow{2}{*}{ OYUG } & JG & $-1,841$ & 1,674 &, 275 \\
& GAG & $3,379^{*}$ & 1,624 &, 040 \\
\hline \multirow{2}{*}{ GAG } & JG & $-5,220^{*}$ & 1,675 &, 003 \\
& OYUG & $-3,379^{*}$ & 1,624 &, 040 \\
\hline
\end{tabular}

Tablo 5e incelendiğinde, sontestte JG ile OYUG arasında anlamlı bir farkın olmadığı $\left(X_{\mathrm{JG}}=165,30, X_{\text {oYuG }}=164,07\right.$ ve $\left.\mathrm{p}=, 275\right)$, JG ile GAG arasında anlamlı farklılığın JG lehine olduğu görülmektedir $\left(X_{\mathrm{GAG}}=160,80 ; X_{\mathrm{JG}}=165,30\right.$ ve $p=, 003)$. Ayrica OYUG ile GAG arasinda anlamlı farklılığın OYUG lehine olduğu görülmektedir (XAG $=160,80 ; \quad$ XoYUG $=164,07$ ve $\mathrm{p}=, 040)$. Bu bulgudan elde edilen istatistiksel sonuçlar, jigsaw yönteminin demokratik tutum üzerinde diğer gruplardan daha etkili olduğunu göstermektedir.

\section{SONUÇ VE ÖNERILER}

Araştırmanın birinci alt problemi kapsamında her bir deney grubunun DTÖ öntest-sontest puanları kendi içinde karşılaştııılmıştır. Yapılan analizler sonucunda tüm deney gruplarının öntest ve sontest puanlarının anlamlı düzeyde değiştiği ve her üçünün de sontest ortalamalarının yükseldiği görülmektedir. Bu bulgular, sosyal bilgiler dersinde her üç işbirlikli öğrenme yönteminin de öğrencilerin demokratik tutumları üzerinde anlamlı düzeyde olumlu etkileri olduğunu göstermektedir.

Araştırmanın ikinci alt problemi kapsamında ise öğrencilerin demokratik tutumları üzerinde hangi yöntemin daha etkili olduğu incelenmiştir. Deney gruplarındaki öğrencilerin uygulamalara başlamadan önce demokratik tutumla- rının hangi düzeyde olduğunu belirlemek için yapılan DTÖ'nün öntest analiz sonuçlarında gruplar arasında istatistiksel olarak anlamlı farkların olduğu sonucuna varılmıştır. Özellikle OYUG ve GAG'da öğrencilerin demokratik tutum öntest puanlarının birbirlerine oldukça yakın JG'deki öğrencilerin ise daha düşük düzeyde olduğu görülmüştür. $\mathrm{Bu}$ sonuçlara göre araştırmaya katılan grupların demokratik tutumları bakımından benzer özellikte olmadıkları söylenebilir. Gruplardaki öğrencilerin demokratik tutum açısından benzer özelliklerde olmamasının sebebi olarak; öğrencilerin farklı çevreden ve farklı sosyo-kültürel yapıya sahip ailelerden gelmiş olması gösterilebilir.

Araştırmada kullanılan ilgili yöntemlerin uygulamaları tamamlandıktan sonra yapılan DTÖ'nün sontest analiz sonuçlarında da gruplar arasında istatistiksel olarak anlamlı farkların olduğu sonucuna varılmıştır. Çalışmaya başlamadan önce özellikle JG'deki öğrencilerin demokratik tutum öntest puanları OYUG ve GAG'daki öğrencilerin puan ortalamalarından daha düşük olmasına rağmen uygulamalar sonunda JG'deki öğrencilerin demokratik tutum sontest puan ortalamalarının diğer iki gruptan anlamlı derecede yüksek olduğu görülmüştür. Bu durum jigsaw yönteminin kendine özgü uygulamalarından kaynaklanabilir. Çünkü jigsaw uygulamalarında öğrenciler hem asıl hem de uzman diye adlandırılan iki farklı 
grupta da yer alarak daha fazla demokratik davranış yaşantısı geçirirler. Bu yöntemde öğrenciler her iki grupta da farklı öğrencilerle birlikte çalıştıkları için daha fazla öğrenciyle etkileşimde bulunurlar. Böylece grup normları oluşturup bunlara uyma ve birbirlerinin fikirlerini dinleyip saygı duyma davranışlarını daha fazla gösterme fırsatı bulurlar. Ancak demokratik tutumlar üzerinde jigsaw yönteminin GA ve OYU'ya göre daha etkili olduğu sonucu, ilgili alan yazındaki araştırmalarla (Şimşek ve diğerleri, 2006; Şimşek ve diğerleri, 2009; Şimşek, 2012) farklılık göstermektedir. Bu farklılı̆̆ın nedeni araştırma gruplarının yaş farkından kaynaklanabilir. Bu araştırma ortaokul öğrencileriyle, söz konusu diğer araştırmalar ise üniversite ve lise öğrencileriyle yürütülmüştür. Yetişkin bireylerde tutumların değişime karşı daha fazla direnç gösterdiği bilinmektedir.

Daha sonraki çalışmalar için sunulabilecek bazı öneriler şöyledir:

1. Jigsawın demokratik tutum üzerinde GA ve OYU'ya göre daha etkili olduğu sonucu farklı çalışmalarla sınanmalıdır.
2. Sosyal bilgiler dersinde öğrencilere demokratik tutumlar kazandırmada özellikle jigsaw yöntemiyle öğretim teşvik edilmelidir.

3. Sosyal bilgiler dersinde İÖ yöntemlerinin uygulamasına yönelik olarak yapılan çalışmalar nitelik ve nicelik yönünden arttırılmalıdır.

4. Benzer çalışmalar farklı sosyo-ekonomik yapıya sahip bölgelerdeki okullarda ve farklı kademelerde de yapılabilir.

5. Sosyal bilgiler dersi konularının öğretiminde İÖ yöntemleri birbirleriyle ve diğer aktif öğrenme yöntemleriyle karşılaştırmalı olarak çalışılabilir.

6. Jigsaw, GA ve OYU'nun demokratik tutumun yanı sıra farklı değişkenler üzerindeki etkileri de farklı çalışmalarla karşılaştırmalı olarak incelenebilir.

7. Tutumların değişime karşı dirençli olduğu düşünülürse söz konusu yöntemlerin demokratik tutumlar üzerindeki etkisi uygulama süreleri daha uzun olan çalışmalarla araştırılmalıdır.

\section{Kaynakça}

Akbaşlı, S., Yanpar-Yelken, T. \& Sünbül, Ö. (2010). Öğretmen adayı demokratik eğilim ölçeği geliştirme çalışması. Uluslararası Avrasya Sosyal Bilimler Dergisi, 1(1), 94-108.

Bawn, S. (2007). The effects of cooperative learning on learning and engagement. Master Dissertation. The Evergreen State College.

Blair, H. (2003). Jump-starting democracy: Adult civic education and democratic participation in three countries. Democratization, 10(1), 53-76.

Büyükkaragöz, S.S (1994). Demokrasi eğitimi ve okul: Demokrasi gündemi. Ankara: Türk Demokrasi Vakfı Yayınları, Sayı: 19.

Büyükkaragöz, S.S. \& Kesici, Ş. (1996). Öğretmenlerin hoşgörü ve demokratik tutumları. Eğitim Yönetimi, 2(3), 353-365.

Büyüköztürk, Ş. (2011). Deneysel desenler: Öntest-sontest kontrol grubu desen ve veri analizi. (3. Baskı). Ankara: Pegem Akademi Yayınevi. 
Cin, M. (2005). Hayat bilgisi ve sosyal bilgilerde kullanılabilecek strateji, yöntem ve teknikler. A. Tanrı̈ğen, (ed.) Hayat Bilgisi ve Sosyal Bilgiler Öğretimi, 120-164, İstanbul: Lisans Yayınevi.

Davis, O.L. (2003). Does democracy in education still live. Journal of Curriculum and Supervision, 19(1), 14.

Demirtaş, A. (2007). Okullarımızda demokrasi eğitimi neden ve nasıl. Çă̆daş Eğitim Dergisi, 32(339), 1012.

Ebrahim, A. (2012). The effect of cooperative learning strategies on elementary students' science achievement and social skills in Kuwait. International Journal of Science and Mathematics Education 10(2), 293-314.

Edwards, M. (2008). Just another emperor? The myths and realities of philanthrocapitalism. New York: Demos and the Young Foundation. http://www.justanotheremperor.org/adresinden erişilmiştir.

Ferguson-Patrick, K. (2012). Developing an inclusive democratic classroom "in action" through cooperative learning. Joint AARE APERA International Conference, Sydney.

Gömleksiz, M. (1988). Demokratik sınıf ortamı açısından Hacettepe Üniversitesi Eğitim Fakültesi öğretim elemanları ve öğrencilerin davranışlarının değerlendirilmesi. Yayımlanmamış Yüksek Lisans Tezi, Hacettepe Üniversitesi Sosyal Bilimler Enstitüsü, Ankara.

Gömleksiz, M. (1993). Kubaşık öğrenme yöntemi ile geleneksel yöntemin demokratik tutumlar ve erişiye etkisi. Yayımlanmamış Doktora Tezi, Çukurova Üniversitesi Sosyal Bilimler Enstitüsü, Adana.

Gürşimşek, I. \& Göregenli, M. (2004). Öğretmen adayları ve öğretmenlerde demokratik tutumlar, değerler ve demokrasiye ilişkin inançlar. Uluslararası Demokrasi Ĕ̆̈itimi Sempozyumu: 20-21 Mayıs 2004, (s.77-85.), Çanakkale.

Harber, C. (2002) Education, democracy and poverty reduction in Africa. Comparative Education, 38(3), 267-276.

Hotaman, D. (2010). Demokratik eğitim: Demokratik bir eğitim programı. Kuramsal Ĕğitimbilim Dergisi, $3(1), 29-42$.

Kaptan, S. (1998). Bilimsel araştırmalar ve istatistik teknikleri (11. Basım). Ankara: Tekışık Web Ofset.

Kıncal, R. (2004). Vatandaşlık bilgisi. Ankara: Nobel Yayın Dağıtım.

Okutan, M. (2010). Türk Eğitim Sistemi'nde demokrasi eğitimi. Uluslararası İnsan Bilimleri Dergisi, 7(1), 938-945.

Sarı, M. \& Sadık, F. (2011). Öğretmen adaylarının demokrasi algıları (Çukurova Üniversitesi Örneği). Uluslararası Ĕ̆itim Programları ve Öğretim Çalışmaları Dergisi, 1(2), 67-82.

Schul, J. E. (2011). Revisiting an old friend: The practice and promise of cooperative learning for the twenty-first century. The Social Studies,102(2), 88-93.

Schweisfurth, M. (2002). Democracy and teacher education: negotiating practice in the Gambia. Comparative Education, 38(3), 303-314.

Senemoğlu, N. (2005). Gelişim ve öğrenme. Ankara: Gazi Kitapevi. 
Smith, B.L. \& MacGregor, J.T. (1992). What is collaborative learning? In collaborative learning: A Sourcebook for Higher Education, Edited by A. Goodsell, M. Maher, and V. Tinto, 9-22. University Park: National Center on Postsecondary T. L. \& A.

Sönmez, V. (2001). Program Geliştirmede Öğretmen El Kitabı, 9.Baskı, Ankara: Anı Yayıncılık.

Sönmez, V. \& Alacapınar, F.G. (2013). Örneklendirilmiş Bilimsel Araştırma Yöntemleri, Ankara: Anı Yayınc1lik.

Stamovlasis, D., Dimos, A. \& Tsaparlis, G. (2006). A study of group interaction processes in learning lower secondary physics. Journal of Research in Science Teaching, 43(6), 556-576.

Şimşek, U. (2012). Effects of cooperative learning methods on social studies undergraduate students' achievement in political science. Energy Education Science and Technology Part B: Social and Educational Studies, Special Issue, 322-328.

Şimşek, U., Doymuş, K., Şimşek, Ü. \& Özdemir, Y. (2004). Öğrencilerin demokratik tutumlarına grupla öğrenme yönteminin etkisinin incelenmesi. Kazım Karabekir Eğitim Fakültesi Dergisi, 9, 387-396.

Şimşek, U., Doymuş, K., Şimşek, Ü., \& Özdemir, Y. (2006). Lise düzeyinde eğitim gören öğrencilerin demokratik tutumlarına işbirlikçi öğrenme yönteminin etkisinin incelenmesi. Atatürk Üniversitesi Sosyal Bilimler Enstitüsü Dergisi, 7(1), 165-172.

Şimşek, U., Doymuş, K. \& Karaçöp, A. (2009). Yükseköğretimde eğitim gören öğrencilerin demokratik tutumlarına jigsaw ve birlikte öğrenme tekniklerinin etkisi. Atatürk Üniversitesi Sosyal Bilimler Enstitüsü Dergisi, 13(1), 167-176.

Toper, T. (2007). İlköğretim ikinci kademede demokrasi eğitimi: İkinci kademe öğretmenlerinin demokratik tutum ve davranışları sergileme düzeyleri (Kars İli Örneği). Yayınlanmamış Yüksek Lisans Tezi, Kafkas Üniversitesi, Kars.

Ural, S.N. (2010). İlköğretim öğrencilerinin demokratik tutum ve empatik eğilim düzeylerine sosyal bilgiler dersinin etkisi. Yayımlanmamış Yüksek Lisans Tezi, Sakarya Üniversitesi Sosyal Bilimler Enstitüsü, Sakarya.

Webb, N.M. (1982). Student interaction and learning in small groups. Review of Educational Research, 52(3), 421-445.

Yeşil, R. (2001). İlköğretim düzeyinde okul ve ailenin demokratik davranışlar kazandırmadaki etkisi. Yayınlanmamış Doktora Tezi, Atatürk Üniversitesi Sosyal Bilimler Enstitüsü, Erzurum.

Yeşil, R. (2002). Okul ve ailede insan hakları ve demokrasi eğitimi. Ankara: Nobel Yayın Dağıtımı.

Yılar, M.B. (2015). Sosyal bilgiler dersinde işbirlikli öğrenme yöntemlerinin öğrencilerin akademik başarılarına, demokratik tutumlarına ve sosyal becerilerine etkileri. Yayımlanmamış Doktora Tezi, Atatürk Üniversitesi Eğitim Bilimleri Enstitüsü, Erzurum. 


\section{Extended Summary}

Many of the studies in the literature has showed that cooperative learning was compared with traditional teaching method. According to the results of these studies, it was also found that cooperative learning is more effective than the traditional teaching method. In this study; jigsaw, group investigation and reading-writig-presentation methods of cooperative learning model were used as independent variables and the effects of these methods on the democratic attitude were comparatively examined.

Quantitative studies that compare the effect of different cooperative learning methods on democratic attude is quite limited. Therefore, this research was expected to contribute to the literature.

Purpose of this study was to determine the effects of jigsaw, group investigation and reading-writingpresentation on the democratic attitude in teaching the unit of "Democracy's Adventure" in the social studies course.

Being one of the quantitative research methods, an experimental design which was pretest-posttest without control group was used in this study. This design is often used in the social sciences. This design is more convenient, useful and effective than a post-test without control group where a pre-test is not used.

The sample of this study consisted of 92 secondary school students from three different classes enrolled in the social studies lesson for the 2012-2013 academic year (43 male, 49 female).

Democratic Attitude Scale (DAS) was developed by Ural (2010). DAS was implemented as both pretest and posttest to the experimental groups to measure the democratic attitude of students and determine whether there is a significant difference or not. The reliability coefficient (KR-20) of DAS was found to be 0,94 .

Three experimental groups were formed to compare effectiveness of jigsaw, group investigation (GA) and reading-writing-presentation (RWP) on the democratic attitude. DAS was applied to the each experimental group as a pre-test before implementation. The students of three experimental groups studied the topics of the unit "Democracy's Adventure" in the social studies course during the same period of time using different instructional methods. The subjects in the three groups studied the "social studies lesson" for five weeks. The researcher carried out the implementation in three groups. After that, DAS was conducted to the experimental groups at the end of the study as a post-test.

The collected data were analyzed by using descriptive statistics, dependent $t$ test, ANOVA, ANCOVA and multiple comparison tests.

According to the results of the study, it was found that pretest-post test scores of each three experimental groups significantly changed and the arithmetic mean of the posttest also increased. These findings show that all three methods were effective in increasing the democratic attitude of the students in social studies lesson.

In the scope of the second research problem of the study, it was found that there were statistically significant differences among groups as a result of DAS's post-test analyses. Although the democratic attitude pre-test scores of the students in JG were lesser than the students in RWPG and GIG before the implementation, at the end of the implementation the democratic attitude post-test scores of the students in JG group were significantly higher than other two groups. This case can be as a result of some implementatons that are specific to jigsaw method. The students experince more democratic attitude by being in two different groups which are called as main and expert in jigsaw implementations. In this method, the students study with different students so they interact with more students. Thus, they have more opportunity to listen and respect each others' ideas and to form group norms and obey to these norms. 